\title{
RELECTURA Y REESCRITURA DE FRANZ KAFKA en cuentos de Roberto Bolaño ${ }^{1}$
}

\author{
EUGENIA FERNÁNDEZ \\ Universidad Nacional de Mar del Plata
}

Recepción: 15 de septiembre de 2020 Aceptación: 10 de diciembre de 2020

Resumen: La producción del escritor chileno Roberto Bolaño propicia la recuperación de escrituras pasadas y propone su reinvención. Nos interesa observar cómo Roberto Bolaño relee a Franz Kafka y lo reescribe en sus cuentos «Últimos atardeceres en la tierra», «Días de 1978», «Vagabundo en Francia y Bélgica» y «Dos cuentos católicos».

Palabras clave: Roberto Bolaño, lectura, reinvención, Franz Kafka.

Abstract: The production of the Chilean writer Roberto Bolaño promotes recovering past writings and reinventing them. We are interested in observing how Roberto Bolaño rereads Franz Kafka and rewrites him in his stories «Últimos atardeceres en la tierra», «Días de 1978», «Vagabundo en Francia y Bélgica» and «Dos cuentos católicos»».

Keywords: Roberto Bolaño, Writing, Reinventing, Franz Kafka.

${ }^{1}$ Este trabajo es un extracto del capítulo 3 de mi tesis doctoral «La escritura de Roberto Bolaño: reinventar la literatura desde una lectura disléxica» defendida en junio de 2020 (Universidad Nacional de Mar del Plata).

AnMal, XLI, 2020, pp. 207-221. 


\section{Introducción}

La lectura es un fenómeno fundante de la escritura en general y de la literatura en particular siempre colmada de reminiscencias de su propio pasado. Barthes (2009: 50-51) entiende la lectura como una «biblioteca», no en tanto institución sino como depositaria del «Deseo de leer»: «La Biblioteca, por su propio estatuto [...] es infinita, en la medida en que siempre se sitúa más acá o más allá de nuestra demanda». Además, esta noción dialoga con la idea de «tradición deseada» de Raymond Williams (1982: 174) en Cultura, donde la define como «un proceso de continuidad deliberada» que «constituye una selección y reselección» continua. De esto se desprende que leer es releer y, en consecuencia, reescribir; resulta ineludible mencionar La dorada garra de la lectura. Lectoras y lectores de novela en América Latina, donde Susana Zanetti (2010: 436) sostiene que «la lectura promueve relaciones intertextuales que van constituyendo el andamiaje sustentador de las tradiciones», y agrega: «se escribe porque se lee, se escribe porque se relee» (2010: 429). Nos interesa observar cómo Roberto Bolaño relee a Franz Kafka y lo reescribe en alguno de sus cuentos, lo coloca en los estantes de su biblioteca y lo hace formar parte de su «tradición deseada».

\section{La trampa kafkiana}

En el Diccionario de la Real Academia Española de la Lengua, el término kafkiano tiene tres acepciones: 1) perteneciente o relativo a Franz Kafka o a su obra, 2) característico de este escritor checo o de su obra, 3) dicho de una situación: absurda, angustiosa.

Eduardo Guerrero del Río

La producción del escritor chileno Roberto Bolaño (Santiago de Chile, 1953 Barcelona, 2003) propicia la recuperación de escrituras pasadas y propone su reinvención. Se trata de un gesto que sostiene su escritura y, como señala J. L. Borges (1974: 712), «el hecho es que cada escritor crea a sus precursores» de tal modo que «su labor modifica nuestra concepción del pasado, como ha de modificar el futuro».

Sergio Cueto (1999: 35) en su artículo «Un discípulo tardío (El Kafka de Borges)» afirma que, según Borges, Kafka devuelve la literatura a su pasado medieval alegórico ya que universaliza lo individual y singulariza lo abstracto. Este concepto de lo universal implica una literatura que no se llena 
de circunstancias (temporales, espaciales, históricas) como la novela moderna, sino que recurre a la alegoría por su capacidad de sugerir «múltiples intuiciones del lector» (Cueto, 1999: 35). La narración alegórica kafkiana en estos términos sería la de un relato oculto que procura descubrir la literatura en su carácter originario y «enseña dos cosas: que la obra no tiene sentido propio, no se basta a sí misma y exige ser leída a modo de ejemplo, y que aquello de lo que ella es ejemplo permanece afuera del sentido, como el afuera del sentido, pero en la intimidad de la obra» (Cueto, 1999: 36). Bolaño, discípulo de Borges y también de Kafka, habría concebido también que la escritura no se basta a sí misma, que el sentido siempre está afuera y que su única exigencia sería la lectura. Dice G. Bataille (2000: 206) lúcidamente que el checo siempre escribió

... haciendo de cada palabra una trampa (edificaba peligrosos edificios en donde las palabras no se ordenan lógicamente, sino unas sostienen a las otras como si sólo pretendieran sorprender, desorientar, como si se dirigieran al propio autor, que nunca se cansó, parece, de ir de sorpresa en sorpresa).

Bolaño se apropia de esta trampa en tanto operación por medio de la cual cada texto refiere siempre a sí mismo en tanto escritura, en tanto literatura.

Por otra parte y salvando las distancias, se podría establecer un paralelo entre la crítica en torno a Bolaño y a Kafka: cuando Blanchot (2006: 85) se pregunta respecto del escritor checo «¿Cómo representarnos ese mundo que se nos escapa, no porque sea inaprehensible, sino porque al contrario tal vez haya demasiado por aprehender», encuentra que «los comentaristas ni siquiera están fundamentalmente en desacuerdo» pero «usan más o menos las mismas palabras: el absurdo, la contingencia, el deseo de conquistar un lugar en el mundo, la imposibilidad de mantenerse en él, el deseo de Dios, la desesperación, la angustia»; sin embargo, «¿de quién hablan?». Podría reconocerse la misma situación respecto de la crítica bolañiana, puesto que su universo textual tendría demasiado por aprehender y lograrlo es complejo, abundan los análisis y/o comentarios que «usan más o menos las mismas palabras»: el mal, la dictadura chilena, el exilio, el horror... Asimismo, se podría preguntar ¿de quién hablan? O ¿hablan de Bolaño? Y, en ese caso surge la contradicción, pues parecería que sus textos proponen precisamente lo contrario: hablar de escritura, lectura, literatura pese a la trampa del nombre propio o los personajes con inicial B por nombre (recordemos el Joseph K. o K a secas, de Kafka).

En el capítulo «Un relato sobre Kafka» de El último lector, Piglia (2005: 51) echa luz sobre el vínculo escritura- vida que caracteriza la obra kafkiana: «No le hace falta mucha realidad a Kafka, un fragmento mínimo le alcanza. [...] Se define así cierto nexo entre la escritura y la vida que no pertenece a la 
categoría de lo autobiográfico». Esto nos recuerda el ensayo «Literatura + enfermedad = enfermedad» de Bolaño que, en superficie, parece relatar los avatares de su disfunción hepática, cuando en realidad se trata de una reflexión sobre literatura y lecturas personales. Bolaño adopta de Kafka un especial modo de leer lo real y convertirlo en material para la literatura. Como sostiene Ricardo Piglia (2005: 52) respecto de Kafka, el efecto de escritura pretendido por Bolaño se produce a partir de un «procedimiento de relacionar "por caminos extraviados" lo que ha vivido con lo que ha escrito, percibir fragmentos de realidad cifrados en los textos» y se lograría a partir «un nuevo modo de leer: la literatura le da forma a la experiencia, la constituye como tal y la anticipa» (Piglia, 2005: 53). La vida se despoja así de realidad y «la lectura suspende la experiencia» y la recompone de otro modo, produciendo cada vez un relato diverso (Piglia, 2005: 57).

Pensemos por ejemplo en «La selva marítima» ${ }^{2}$ donde Bolaño intenta construir la atmósfera de lugares como Lloret de Mar, Tossa y Blanes. Este último escenario remite menos a la ciudad española donde Bolaño vivió desde 1985 hasta su muerte que a la de Juan Marsé:

En Blanes no hay fantasmas sino pura energía. Ya no recuerdo cuando llegué aquí. Sólo sé que fue en tren y hace muchos años. Juan Marsé, en Últimas tardes con Teresa, convirtió Blanes en el paraíso inalcanzable de todos los Julien Sorel de España. Yo leí la novela en México y la sonoridad de la palabra Blanes (que viene del latín Blanda) me subyugó. Todos somos el Pijoaparte, pero yo nunca sospeché que llegaría un día a Blanes y que ya nunca más desearía marcharme (Bolaño, 2004: 238).

Blanes se convierte en este fragmento en escenario de dos novelas disímiles pero hermanadas por la relectura de Bolaño quien lee en el Julien Sorel de Stendhal, el Pijoaparte de Marsé. Entonces, la ciudad costera lejos de ser una zona geográfica se instaura en la crónica como un teatro (escenografía) que se descubre no a través de un recorrido turístico, sino de la literatura de Últimas tardes con Teresa ${ }^{3}$. El título de esta novela resuena en el relato de Bolaño «Últimos atardeceres en la tierra» del volumen Putas asesinas (2001), donde no encontraremos al Pijoaparte ni a Teresa, pero sí la atmósfera de Blanes, un espacio cuyo ambiente subyuga al lector.

Este modo de construir el espacio nos reenvía a Kafka. Sus comentaristas coinciden en describir su prosa como densísima, claustrofóbica y casi

\footnotetext{
2 Perteneciente a la sección «Escenarios» del volumen Entre paréntesis (2004) donde se reúnen algunas crónicas de viaje por diversos pueblos y ciudades de España.

${ }^{3}$ Recordemos que esta novela de Juan Marsé, publicada en 1966, relata el romance entre una joven universitaria, burguesa y falsamente rebelde (Teresa), y un seductor ladrón de motos (Manolo Reyes apodado Pijoaparte), que se hace pasar por obrero militante revolucionario.
} 
desesperante ante la futilidad de esfuerzos sostenidos de los personajes por lograr un objetivo imposible, de manera que el lector se desespera junto al personaje ante la situación. Sin embargo, se produce ese efecto a partir de la escritura que se expone a sí misma en tanto deseo del escritor por llevar a cabo su propósito (contar), destinado al fracaso. La narración en «Últimos atardeceres en la tierra» se estructura a partir del desastre en términos de Blanchot y al igual que Kafka más que del deambular de los personajes trata sobre los obstáculos en los intentos por lograr un objetivo literario: «el desastre es lo que no puede acogerse sino como la inminencia que gratifica, la espera del no poder» (Blanchot, 1990: 17). Vale apuntar que el cuento de Bolaño mencionado narra el viaje en coche del protagonista, B, y su padre a Acapulco:

[...] comienza un período gélido, un período aparentemente normal pero dominado por unos dioses helados (dioses que, por otra parte, no interfieren en nada con el calor reinante en Acapulco), unas horas que, en otro tiempo, tal vez cuando era adolescente, B llamaría aburrimiento, pero que ahora de ninguna manera llamaría así, sino más bien desastre, un desastre peculiar, un desastre que por encima de todo aleja a B de su padre, el precio que tienen que pagar por existir (Bolaño, 2001: 56).

Las horas son lentas, la incomunicación entre padre e hijo se profundiza a medida que la historia avanza; sin embargo no hay remordimientos, odio ni reproches, simplemente los días pasan y pareciera estar cada uno en su mundo hasta que sobreviene lo que B llama el «desastre», la pelea final, inconclusa en el texto. Esta síntesis no puede dar cuenta de «la angustia de leer», pues, señalamos, luego de casi veinte páginas sin que nada suceda, apenas inicia lo que podría considerarse un conflicto narrativo que, por otra parte, queda suspendido de modo abrupto. Este texto, siguiendo a Blanchot (1990: 17), «está vacío, no existe en el fondo; hay que cruzar un abismo, y no se entiende si no se da ese salto». Un salto posible sería dejar la historia triste del viaje de un padre y un hijo que intentan restablecer una distancia insalvable, cruzar el abismo de la escritura y leer el relato de la escritura misma. Según Blanchot (1990: 35): «Cuando todo está dicho, lo que queda por decir es el desastre, ruina de habla, desfallecimiento por la escritura, rumor que murmura: lo que queda sin sobra (lo fragmentario)». El final de «Últimos atardeceres...» pone en evidencia el desastre, en términos blanchotianos (1990: 31), «lo que no tiene lo último como límite», lo inconcluso, lo fragmentario:

Lo que sigue es caótico: en la mesa donde juega su padre todos se han puesto de pie. Uno de los desconocidos grita a todo pulmón. B no tarda en darse cuenta de que está insultado a su padre. [...] Después su padre camina un poco encorvado hacia la salida y B le concede espacio 
suficiente para que se mueva a sus anchas. Mañana nos iremos, mañana volveremos al D. F., piensa B con alegría. Comienzan a pelear (Bolaño, 2001: 62, 63).

La incertidumbre de lo inacabado se encierra en la frase final del cuento, «comienzan a pelear», dado que la tercera persona plural no especifica el sujeto de la acción. No queda claro quiénes comienzan a pelear: bien podría ser el padre que pelea con los jugadores del bar que le reclaman el dinero apostado; o también, el padre que comienza a pelear por fin (la tensión entre padre e hijo nunca se desata) con el hijo. El significado unívoco, imposibilidad del lenguaje, se pierde en esa oración del final y da lugar desde el vacío a la multiplicidad de interpretaciones. Esa fracción de lenguaje («comienzan a pelear») fragmenta la escritura y «lo que hace angustioso nuestro esfuerzo por leer no es la coexistencia de interpretaciones diferentes; es, para cada tema, la posibilidad misteriosa de aparecer ya con un sentido negativo, ya con uno positivo» (Blanchot, 2006: 88). Bolaño relee y reescribe la literatura de la interrupción, el arte de narrar la interferencia al modo kafkiano, en términos de Blanchot (2004: 74), el impedimento de Kafka de «terminar la mayor parte de sus "historias" 》. Esto es lo que le interesa reinventar a Bolaño porque no se trata de un déficit de Kafka sino de una decisión deliberada de evitar todo desenlace: llevan «en sí la felicidad de una verdad definitiva». Kafka sabía que el lenguaje no es portador de verdad, pues para ello debería representar unívocamente lo real. En El último lector, Piglia (2005: 45) advierte que «la interrupción» es el «gran tema de Kafka, la interferencia que impide llegar a destino» y es lo que «define también el registro de su escritura»: «la suspensión, el desvío, la postergación» constituyen «su estilo».

«Últimos atardeceres...» cuya escritura se aferra al puro presente y se desliza hacia un final inconcluso construye un lector espectador de un viaje que no posee un itinerario fijo y lo coloca en el lugar incierto de la espera de algo que párrafo a párrafo está por suceder. Se trata de un relato que trabaja como su narrativa en general la incertidumbre, instaurándola. En Roberto Bolaño. Una literatura infinita, Chris Andrews (2005: 33) reflexiona sobre este rasgo en «Algo va a pasar: los cuentos de Roberto Bolaño», y afirma que

los cuentos de Roberto Bolaño tienen al lector en vilo sin conformarse a modelos catalogados. ¿Cómo explicar la eficacia de estos cuentos que parecen burlarse de las leyes del género y dan la impresión de ser productos de una improvisación o una deriva continua?

Lo nuevo en la escritura bolañiana sería la puesta en escena de la escritura misma efectuándose (a la manera de los vanguardistas). Recordemos que el relato inicia con la frase «La situación es ésta», luego, avanzada la historia 
advierte que «algo va a pasar», es decir, pone al descubierto lo que debería estar oculto, las partes de la estructura del cuento (situación inicial y conflicto): «¿Qué va a pasar?, dice B. Algo malo, dice la mujer. ¿Cómo cuánto de malo?, dice B. No lo sé, pero yo que tú me largaría» (Bolaño, 2001: 61). El orden tradicional (situación inicial - conflicto - resolución) no se rompe, más bien se satura: la primera parte que debería ser breve según el género, dijimos, se extiende por cerca de veinte páginas, la segunda, si bien ocupa seis páginas, nunca formula un conflicto claro, apenas la proximidad del desastre que no se resolverá porque la tercera parte comprende sólo la oración final, abierta, «comienzan a pelear». En este cuento de Bolaño, la secuencia narrativa tradicional no sufre una ruptura experimental que consistiría, por ejemplo, en invertirla y el orden se mantiene; la anomalía de la secuencia aquí se produce al exponer las partes de la estructura, al explicitar los mecanismos organizativos del artefacto, su andamiaje («la situación es ésta», «algo va a pasar»). Este método del escritor chileno sería un modo de reinventar el procedimiento kafkiano que Blanchot define como el «arte de narrar la interferencia», por consiguiente la interrupción no consiste únicamente en un corte, una detención, sino en la obstrucción del desarrollo del relato, sería por ello una escritura que se estorba a sí misma y se muestra en su imposibilidad de significar.

En consonancia, el personaje en tanto procedimiento del relato también queda al descubierto y contribuye a esa escritura; la nominación misma, por ejemplo, se ve interferida: el protagonista se llama B, el resto del nombre está elidido y el segundo personaje importante no tiene nombre, es sólo «el padre de B». Como el K de Kafka, B aparece en varios textos breves de Bolaño y los estatutos autor / personaje se enlazan en la intención de fracturar categorías literarias. En relatos como «Un sueño» o novelas como El castillo, Kafka entabla el juego de la confusión sujeto autoral / narrador nombrando a los protagonistas con la misma inicial de su apellido (K); así, en «Una confusión cotidiana», los personajes se exhiben como puro lenguaje, sólo son letras:

Un suceso cotidiano; su resultado: una confusión cotidiana [...]. A pesar de esa incomprensible conducta, B entró en la casa a esperar su vuelta. Y ya había preguntado muchas veces si no había regresado aún, pero seguía esperándolo siempre en el cuarto de A. Feliz de hablar con B y de explicarle todo lo sucedido, A corre escaleras arriba. Casi al llegar tropieza, se tuerce un tendón y a punto de perder el sentido, incapaz de gritar, gimiendo en la oscuridad, oye a B - tal vez muy lejos ya, tal vez a su lado- que baja la escalera furioso y que se pierde para siempre (Kafka: 507, 508).

La primera oración nos regresa al inicio de «Últimos atardeceres...» («la situación es ésta»), que aparece seguida de dos puntos y podría leerse como 
reescritura de «un suceso cotidiano; su resultado: una confusión cotidiana». El magisterio de Kafka sobre Bolaño se sintetiza en un método de escritura que trabaja sobre y con la incertidumbre ya que, como explica Blanchot en El espacio literario, sus relatos

[...] son fragmentos, el conjunto de la obra es un fragmento. Esta carencia podría explicar la incertidumbre que hace inestables, sin cambiar su dirección, la forma y el contenido de sus lecturas. Pero esta carencia no es accidental, se halla incorporada en el sentido mismo que mutila; coincide con la representación de una ausencia que ni se tolera ni rechaza $[\ldots](2006: 87-88)$.

La incertidumbre se resume en la multiplicidad de lecturas del texto literario que algunos comentaristas consideran el fracaso de la escritura, la imposibilidad de lograr un objetivo literario. Sin embargo, si Kafka se esforzaba por escribir y sus intentos no tenían fin, Bolaño escribe el esfuerzo mismo de la escritura: lo fragmentario, lo inconcluso, legado kafkiano asumido, que paradójicamente la sostiene.

\section{Más trampas kafkianas}

En «Dos cuentos católicos» perteneciente a El gaucho insufrible también se observa una puesta en escena de mecanismos de escritura en el texto mismo. Se trata de un relato doble (o desdoblado): consta de dos partes, «I. La vocación» $\mathrm{y}$ «II. El azar», subdivididas cada una en treinta tramos numerados. En la primera, un joven de diecisiete años con vocación de cura libra una lucha interna con su angustia adolescente, y en la segunda, un hombre escapa de un manicomio (luego de asesinar a un monje pederasta y a un niño) disfrazado de monje. En principio parecen dos historias independientes (aunque de temática católica) pero hacia el final de la segunda parte el lector percibe que ambos relatos transcurren en la misma ciudad y que el monje descalzo, que el adolescente sigue por las calles hasta que sube al tren, es el mismo hombre escapado del manicomio y ladrón de las ropas de su víctima. El instante de la mirada del adolescente y el reconocimiento del asesino de ser perseguido por alguien se produce en ambas historias en el mismo número de sección, la 26:

26. Pero no era una sombra sino un monje. A juzgar por el hábito podía ser un franciscano. [...] 28. Iba descalzo (Bolaño, 2003: 123) [«I. La vocación»]. 
26. Iba descalzo y hacía frío. [...] Al cabo de unos metros noté que alguien me seguía [...] (Bolaño, 2003: 133) [«II. El azar»].

El joven persigue al falso religioso por curiosidad y porque lo cree verdadero, un modelo a seguir, y sin saber que no es un monje ni lo que ha hecho, lo admira e interpreta sus movimientos como actos devotos: los pies descalzos producto de la huida luego del crimen son leídos por el joven como un signo de pobreza característico de los franciscanos, y la cabeza gacha del asesino que pretende no ser visto, una postura acorde con la oración. En la segunda parte encontramos otra perspectiva: si el adolescente observa al criminal y se siente atraído por su aparente santidad, el homicida percibe su mirada y siente rechazo especulando que «seguramente era el hijo de una puta del cerro del Moro» (Bolaño, 2003: 134). Las miradas se cruzan, se produce el encuentro, pero el reconocimiento es paradójico: el muchacho devoto que ansía ser cura es percibido como «el hijo de una puta» y el criminal como un católico fervoroso. Las comillas que colocamos en la palabra «otra» que precede a «perspectiva» en nuestra penúltima oración anticipan que finalmente no se trata de puntos de vista opuestos, sino que ambos, el joven y el asesino, llevan a cabo la misma operación: leen los signos (atuendos, movimientos, gestos, miradas) a su antojo e interpretan en consecuencia. La forma de la escritura, ese mecanismo que desdobla la historia, simula perspectivas contrapuestas. De modo que el instante del encuentro, a la manera borgeana, sufre una inversión o alteración en tanto que no se produce el reconocimiento del protagonista en el otro sino que el cruce de miradas de los personajes en «Dos cuentos católicos» muestra el acto mismo de lectura que puede ser no solo diverso sino opuesto. La lectura que el adolescente y el asesino hacen respectivamente del otro se vuelve en el texto un modo de metacomunicar la imposibilidad de decodificación de la escritura literaria unidireccionalmente. Podría leerse al joven como un equivalente de la figura del lector inocente que lee signos de manera literal (al ver el atuendo de monje, sencillamente interpreta que se trata de un monje y no percibe el disfraz). Y al homicida se lo podría ver semejante a un lector que lee a su modo (ve en el joven al «hijo de una puta» y lo interpreta como un peligro, cuando no lo es). El lector bolañiano es arrastrado por la misma imposibilidad de decodificar y necesita la relectura para formular una interpretación propia que será una más entre muchas.

Hemos señalado que Bolaño asume, de la herencia de Kafka, la vocación de la «trampa». Así, a través de la doble escena, encuentra el modo de mostrar cómo su escritura obliga a regresar y reexaminar el mismo texto durante su lectura y deviene entonces en un movimiento fundado en la lectura - escritura, en el caso del lector, que escribe su propio texto, su propia lectura.

En «Consejos sobre el arte de escribir cuentos» (Entre paréntesis) Bolaño (2004: 324$)$ advierte que nunca se deben abordar «los cuentos de uno en uno» 
porque «uno puede estar escribiendo el mismo cuento hasta el día de su muerte»; asimismo, que «la tentación de escribirlos de dos en dos es tan peligrosa como dedicarse a escribirlos de uno en uno y además lleva en su interior el juego más bien pegajoso de los espejos amantes: una doble imagen que produce melancolía». Bolaño escribiría los dos cuentos católicos «de dos en dos»; no obstante (más allá de la imagen melancólica del adolescente ingenuo que cree al asesino un monje casto y devoto), sí hay dos historias en «Dos cuentos católicos»: la de la doble mirada de la religión de los protagonistas y la del mecanismo de escritura del texto mismo. Esta operatoria refrenda ciertos postulados de Piglia en la sección «Tesis sobre el cuento» de Formas Breves donde resuena la cita anterior de Bolaño:

Primera tesis: un cuento siempre cuenta dos historias. [...] El arte del cuentista consiste en saber cifrar la historia 2 en los intersticios de la historia 1. Un relato visible esconde un relato secreto, narrado de un modo elíptico y fragmentario (2014: 104).

Detrás de «Dos cuentos católicos» se puede descifrar el relato oculto o secreto del oficio de la escritura construido «con lo no dicho, con el sobrentendido y la alusión» (Piglia, 2014: 106). Bolaño parece apropiarse de lo que Piglia (2014: 107) define como la inversión que funda lo kafkiano: «Kafka cuenta con claridad y sencillez la historia secreta, y narra sigilosamente la historia visible hasta convertirla en algo enigmático y oscuro». Así, la estrategia compositiva del relato oculto se funda en otro legado insoslayable para la escritura bolañiana, el borgeano:

Para Borges la historia 1 es un género y la historia 2 es siempre la misma. Para atenuar o disimular la esencial monotonía de esa historia secreta, Borges recurre a las variantes narrativas que le ofrecen los géneros. Todos los cuentos de Borges están construidos con ese procedimiento. [...] La historia visible [...] sería contada por Borges según los estereotipos (levemente parodiados) de una tradición o de un género (Piglia, 2014: 108).

Bolaño narra de un modo elíptico la tarea del escritor siguiendo el modelo de Borges, quien «(como Poe, como Kafka), sabía transformar en anécdota los problemas de la forma de narrar» (Piglia, 2014: 109). Ese procedimiento borgeano sería renovado por Bolaño a través de su gesto de reinvención cuando reescribe, de nuevo, los estereotipos reescritos por Borges. Volviendo a Kafka, lo que Piglia (2014: 109) apunta para el cuento permitiría definir lo que describimos como la herencia asumida: «el cuento se construye para hacer aparecer artificialmente algo que estaba oculto». 
Los «dos cuentos católicos» son en realidad uno solo; por su organización podrían superponerse ambas enumeraciones de fragmentos y narrarse una sola historia. El orden está a la vista y si intercalamos los segmentos, por parejas iguales de números, logramos unificar la historia; pero nos parece que el propósito del texto es mostrar la escritura como un laboratorio.

En muchos de sus cuentos Bolaño distorsiona intencionalmente el relato secreto colocando en superficie, como historia visible, su propia vida y, así, conduce la lectura hacia la interpretación autobiográfica. Sucede con la crítica algo similar a lo que ocurría con Kafka puesto que «para muchos de sus comentaristas, admirar a Kafka antes que nada es situarlo fuera de su condición de escritor» (Blanchot, 2006: 97). Los textos bolañianos en muchos casos han sido más objeto de homenaje y rendición de culto que de lectura y análisis crítico detenido y extendido. La tensión literatura — vida está presente en sus textos y la misma escritura fomenta esa lectura, pero refiere a la condición de escritor y su oficio, no (exclusivamente) a datos biográficos e históricos. En Putas asesinas, además de «Últimos atardeceres en la tierra» hallamos dos relatos cuyo protagonista es su llamado alter ego B: «Días de 1978» y «Vagabundo en Francia y Bélgica», ambos escritos en tiempo presente y tercera persona. En apariencia narran experiencias que se corresponderían con la biografía de Bolaño ya que el primer cuento citado transcurre en 1978 y B está en México en una fiesta de exiliados chilenos, y en el segundo viaja por Francia y Bélgica buscando a Henri Lefebvre, también rodeado de exiliados: una vez más la escritura invita a caer en la trampa de la «vieja» confusión realidad / ficción.

En el relato «Días de 1978», en el contexto de una cena en casa de unos amigos chilenos, B cuenta una película de Tarkovski:

En su memoria esta película está marcada a fuego. Aún hoy la recuerda incluso en pequeños detalles. En esa época la acababa de ver, así que su narración debió de ser, por lo menos, vívida. La película cuenta la historia de un monje pintor de iconos en la Rusia medieval. A través de las palabras de B, van desfilando los señores feudales, los popes, los campesinos, las iglesias quemadas, las envidias, la ignorancia, las fiestas y un río de noche, las dudas y el tiempo, la certeza del arte, la sangre que es irremediable (Bolaño, 2001: 75).

Con seguridad un comentarista podría señalar la admiración de Bolaño respecto de la película Andrei Rublev $(1966)^{4}$ y establecer un paralelo con B. Evitada esa línea de interpretación, indicaremos que la narración de la película

\footnotetext{
${ }^{4}$ Reiteramos que no nos extenderemos en el vínculo literatura y cine en la escritura bolañiana por cuestiones de espacio, mas destacamos la importancia de un análisis de este aspecto en el universo Bolaño que constituye otro eje de interés para futuras investigaciones.
} 
se extiende por las tres páginas siguientes y que al finalizar, la cena acaba con la partida de los invitados y la referencia al suicidio de uno de ellos (U) con quien $\mathrm{B}$ había protagonizado una pequeña riña en otra velada, lo cual hasta el momento parece el conflicto del relato. Si la tensión en la relación entre B y U es la historia visible, habría un relato secreto, el de la película, que propone una relectura del clásico de Tarkovski, cuyos protagonistas, un monje y un adolescente, nos regresan a «Dos cuentos católicos» que pueden (uso plural insistiendo en que se trata de doble relato) releerse ahora como otra reescritura del film. La relectura de la película rusa en «Días de 1978» está centrada en el arte de la construcción de campanas en tanto oficio que se aprende por medio de la observación del maestro (el padre del adolescente), pero sin ayuda, en soledad. Habría un relato secreto en clave cinematográfica del oficio solitario de la literatura que se aprendería por medio de la lectura de los maestros: «El adolescente mira al monje y le dice que su padre, ese cerdo borracho, jamás le enseñó el arte de la construcción de campanas, que prefirió morirse llevándose el secreto consigo, que él aprendió solo, mirándolo. Y luego sigue 1lorando» (Bolaño, 2001: 77).

En el mismo sentido, «Vagabundo en Francia y Bélgica», el relato de la errancia por ambos países (no se trata de un viaje) y el romance breve de $\mathrm{B}$ y M (personaje femenino) ocultarían el relato de la búsqueda de Henri Lefebvre, cifra de la crítica a la vida cotidiana. Tanto este relato de Bolaño (como «Días de 1978» y «Últimos atardeceres en la tierra», por ejemplo) narran escenas cotidianas mínimas, una cotidianeidad que se constituye de momentos fugaces y vagos. La figura de Lefebvre, contemporáneo del protagonista $\mathrm{B}$, reenvía en el relato a la idea de que las costumbres con su temporalidad ahistórica no harían más que reproducir y perpetuar las relaciones de dominación dado que la cotidianidad sería depositaria de convenios y mentiras del poder, lo que traería como consecuencia el impedimento de que la fantasía y la inventiva encuentren vías para la propia expresión. Además, según Lefebvre $^{5}$ el arte moderno pone las condiciones de la supresión de la cotidianidad a través de la experimentación por ejemplo, al modo de los surrealistas (movimiento al cual perteneció en su juventud). Si bien «Vagabundo en Francia y Bélgica» no posee referencias temporales, podría formar parte de «Días de 1978» dado que narra otro fragmento de la vida del mismo personaje B. Nuevamente Bolaño coloca la trampa, de manera que la búsqueda de Lefebvre remite a la fundación del movimiento Infrarrealista en 1976 cuyo manifiesto concluye con sus premisas:

\footnotetext{
${ }^{5}$ Seguimos a Lefebvre (1972) en La vida cotidiana en el mundo moderno.
} 
Hacer aparecer las nuevas sensaciones - Subvertir la cotidianeidad. O. K.

DÉJENLO TODO, NUEVAMENTE

LÁNCENSE A LOS CAMINOS (Madariaga, 2001: 151).

En el volumen Llamadas telefónicas (1997), «Una aventura literaria» también tiene como protagonista a B y nos regresa además a otro de sus cuentos, «El viaje de Álvaro Rousselot», al narrar la historia de un escritor que publica una novela donde se burla de un contemporáneo, A, más famoso y leído que él, quien luego escribe reseñas elogiosas sobre sus obras. El misterio se produce cuando la última crítica de A aparece apenas dos días después de la publicación de la última novela de $\mathrm{B}$ quien la lee como una venganza irónica por su burla. El resto trata las elucubraciones de $\mathrm{B}$ respecto de los propósitos de $\mathrm{A}$ y se obsesiona con el encuentro en persona con quien se ha convertido en su principal lector. «Una aventura literaria» finaliza exactamente en el instante del encuentro y este queda, al modo kafkiano, en suspenso, fragmentado:

En el rellano junto a la puerta abierta, A lo está esperando. Es alto, pálido, un poco más gordo que las fotos. Sonríe con algo de timidez. B siente por un momento que toda la fuerza que le ha servido para llegar a casa de A se evapora en un segundo. Se repone, intenta una sonrisa, alarga la mano. Sobre todo, piensa, evitar escenas violentas, sobre todo evitar el melodrama. Por fin, dice A, cómo estás. Muy bien, dice B. (Bolaño, 1997: 62).

Si bien B se propone evitar la violencia, en esa afirmación está contenida la posibilidad de lo contrario. El desastre está latente aunque ninguna frase como «comienzan a pelear» esté escrita, entonces la tensión está puesta en las palabras «por fin». El juego de especulaciones previo a este momento carga de incertidumbre el instante del encuentro y no se resuelve, pues a pesar de concretarse para el lector solo queda, en términos blanchotianos, el desastre, lo inconcluso. «Una aventura literaria» reescribe enfrentando finalmente a B y a A (y en lugar de una escalera, el medio es un ascensor) el final de «Una confusión cotidiana» de Kafka, donde los personajes no logran consumar la cita:

Feliz por poder aún hablar con B y aclarárselo todo, A sube corriendo la escalera. Está ya casi arriba cuando tropieza, tiene un desgarramiento en el tendón, y, casi desvanecido por el dolor, incapaz de gritar, solamente gimiendo en la oscuridad, oye - sin poder distinguir si a gran distancia o muy cerca de él— que B, dando enérgicas zancadas, baja la escalera y desaparece definitivamente (Kafka, 2006: 508). 
Bolaño se propone seguir escribiendo cuando toda la literatura ya ha sido hecha, impulso que retoma de Kafka. En el último apartado de su ensayo más importante, «Literatura + enfermedad = enfermedad», Bolaño cierra sus reflexiones describiendo a Kafka como faro de su escritura:

[...] Kafka comprendía que los viajes, el sexo y los libros son caminos que no llevan a ninguna parte, y que sin embargo son caminos por los que hay que internarse y perderse para volverse a encontrar o para encontrar algo, lo que sea, un libro, un gesto, un objeto perdido, para encontrar cualquier cosa, tal vez un método con suerte: lo nuevo, lo que siempre ha estado allí (Bolaño, 2003: 158).

\section{BIBLIOGRAFÍA}

ANDREWS, C. (2005): "Algo va a pasar: los cuentos de Roberto Bolaño», en F. Moreno (coord.), Roberto Bolaño Una literatura infinita, Université de Poitiers CNRS, Monts.

BARTHES, R. (2009): El susurro del lenguaje. Más allá de la palabra y de la escritura, Ed. Paidós, Barcelona.

BATAILlE, G. (2000): «¿Es preciso quemar a Kafka?», en La literatura y el mal. En línea: elaleph.com [consulta: 15 julio 2020].

Blanchot, M. (1990): La escritura del desastre, Monte Ávila, Caracas.

- (2004): El espacio literario, Paidós, Barcelona.

(2006): De Kafka a Kafka, FCE, México D.F.

BOLAÑO, R. (1997): Llamadas telefónicas, Anagrama, Barcelona.

(2001): Putas asesinas, Anagrama, Barcelona.

(2003): El gaucho insufrible, Anagrama, Madrid.

(2004): Entre paréntesis, Anagrama, Barcelona.

BORGES, J. L. (1974): «Kafka y sus precursores», en Obras completas 19231972. Emecé, Bs.As.

Cueto, S. (1999): «Un discípulo tardío. (El Kafka de Borges)», Boletín del Centro de Estudios de Teoría y Crítica Literaria, Boletín 7, Beatriz Viterbo Editora, Rosario, pp. 34-40.

KAFKA, F. (2006): Relatos completos, Losada, Madrid.

LEFEBVRe, H. (1972): La vida cotidiana en el mundo moderno, Alianza, Madrid.

MADARIAGA, M. (2011): Bolaño Infra: 1975-1977. Los Años que inspiraron Los Detectives Salvajes, Ril Editores, Sgo. Chile. 
PigLiA, R. (2005): El último lector, Anagrama, Barcelona. (2014): Formas breves, Debolsillo (Mondadori S. A.), Bs. As.

WiLliams, R. (1982): Cultura. Sociología de la comunicación y del arte, Paidós, Barcelona.

ZANETTI, S. (2010): La dorada garra de la lectura, Beatriz Viterbo Editora, Rosario. 